NASA/TM-2002-211569

ARL-TR-2748
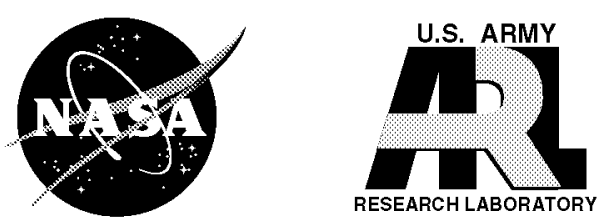

\title{
Self-Recirculating Casing Treatment Concept for Enhanced Compressor Performance
}

Michael D. Hathaway

U.S. Army Research Laboratory, Glenn Research Center, Cleveland, Ohio 
The NASA STI Program Office ... in Profile

Since its founding, NASA has been dedicated to the advancement of aeronautics and space science. The NASA Scientific and Technical Information (STI) Program Office plays a key part in helping NASA maintain this important role.

The NASA STI Program Office is operated by Langley Research Center, the Lead Center for NASA's scientific and technical information. The NASA STI Program Office provides access to the NASA STI Database, the largest collection of aeronautical and space science STI in the world. The Program Office is also NASA's institutional mechanism for disseminating the results of its research and development activities. These results are published by NASA in the NASA STI Report Series, which includes the following report types:

- TECHNICAL PUBLICATION. Reports of completed research or a major significant phase of research that present the results of NASA programs and include extensive data or theoretical analysis. Includes compilations of significant scientific and technical data and information deemed to be of continuing reference value. NASA's counterpart of peerreviewed formal professional papers but has less stringent limitations on manuscript length and extent of graphic presentations.

- TECHNICAL MEMORANDUM. Scientific and technical findings that are preliminary or of specialized interest, e.g., quick release reports, working papers, and bibliographies that contain minimal annotation. Does not contain extensive analysis.

- CONTRACTOR REPORT. Scientific and technical findings by NASA-sponsored contractors and grantees.
- CONFERENCE PUBLICATION. Collected papers from scientific and technical conferences, symposia, seminars, or other meetings sponsored or cosponsored by NASA.

- SPECIAL PUBLICATION. Scientific, technical, or historical information from NASA programs, projects, and missions, often concerned with subjects having substantial public interest.

- TECHNICAL TRANSLATION. Englishlanguage translations of foreign scientific and technical material pertinent to NASA's mission.

Specialized services that complement the STI Program Office's diverse offerings include creating custom thesauri, building customized data bases, organizing and publishing research results ... even providing videos.

For more information about the NASA STI Program Office, see the following:

- Access the NASA STI Program Home Page at http://www.sti.nasa.gov

- E-mail your question via the Internet to help@sti.nasa.gov

- Fax your question to the NASA Access Help Desk at 301-621-0134

- Telephone the NASA Access Help Desk at 301-621-0390

- Write to: NASA Access Help Desk NASA Center for AeroSpace Information 7121 Standard Drive Hanover, MD 21076 
NASA/TM-2002-211569

ARL-TR-2748
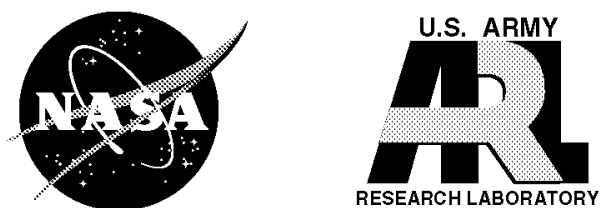

\section{Self-Recirculating Casing Treatment Concept for Enhanced Compressor Performance}

Michael D. Hathaway

U.S. Army Research Laboratory, Glenn Research Center, Cleveland, Ohio

Prepared for the

Turbo Expo 2002

cosponsored by the American Society of Mechanical Engineers

and the International Gas Turbine Institute

Amsterdam, The Netherlands, June 3-6, 2002

National Aeronautics and

Space Administration

Glenn Research Center

July 2002 


\section{Acknowledgments}

My thanks to Ms. Sonia Ensenat for her early efforts in support of this research and to Dr. Anthony J. Strasizar and Dr. Edward M. Greitzer for their efforts in suggesting and initiating this research effort.

Available from

NASA Center for Aerospace Information 7121 Standard Drive

Hanover, MD 21076
National Technical Information Service 5285 Port Royal Road Springfield, VA 22100

Available electronically at htp://gltrs.grc.nasa.gov/GLTRS 


\title{
SELF-RECIRCULATING CASING TREATMENT CONCEPT FOR ENHANCED COMPRESSOR PERFORMANCE
}

\author{
Michael D. Hathaway \\ Vehicle Technology Directorate \\ U.S. Army Research Laboratory \\ Cleveland, Ohio 44135
}

\begin{abstract}
A state-of-the-art CFD code (APNASA) was employed in a computationally based investigation of the impact of casing bleed and injection on the stability and performance of a moderate speed fan rotor wherein the stalling mass flow is controlled by tip flow field breakdown. The investigation was guided by observed trends in endwall flow characteristics (e.g., increasing endwall aerodynamic blockage) as stall is approached, and based on the hypothesis that application of bleed or injection can mitigate these trends. The "best" bleed and injection configurations were then combined to yield a selfrecirculating casing treatment concept. The results of this investigation yielded: 1) identification of the fluid mechanisms which precipitate stall of tip critical blade rows, and 2) an approach to recirculated casing treatment which results in increased compressor stall range with minimal or no loss in efficiency. Subsequent application of this approach to a high speed transonic rotor successfully yielded significant improvements in stall range with no loss in compressor efficiency.
\end{abstract}

\section{INTRODUCTION}

The current trend toward increased pressure rise per stage and increased blade aerodynamic loading tends to reduce the stable operating range of compressors. To provide adequate stall margin the compressor may operate away from the optimum efficiency point. Alternatively, methods may be devised to extend the stable operating range of the compressor. Over the last 30 years various forms of casing treatment have been employed for enhancing compressor stall range, generally though at the expense of compressor efficiency (e.g., Koch, and Smith, 1968a and 1968b, Prince, et al., 1974, Janssens and
Chedozeau, 1979, Takata and Tsukada 1997, Crook, et al., 1993).

Some modern casing treatment concepts utilize the compressor static pressure rise to provide for a recirculation of high-pressure fluid from the rear to the front of a compressor rotor through a path contained within the compressor casing (Koff, et al., 1994, Hobbs, 1995, Nolcheff, 1995). The highpressure fluid is then reinjected at the casing to energize the low momentum fluid in the compressor endwall that contributes to compressor stall range limitations. Such recirculated casing treatment concepts have shown promise for providing the greatest stall range capability with minimum decrement to compressor efficiency of any previous casing treatment concepts, however, for modern well designed compressors they still result in an efficiency penalty.

The genesis of the research reported herein was based on: 1) Recognition that there is still room for improving the effectiveness of casing treatments while reducing or eliminating their detrimental impact to compressor performance, 2) A validated capability of state-of-the-art computational fluid dynamic analysis codes to provide reasonably accurate predictions of compressor rotor endwall flow fields, and 3) A belief that improved understanding of the compressor endwall flow phenomena which limit compressor stall range will lead to improved effectiveness of recirculated casing treatments. As such, the goal of this research program was to develop an improved casing treatment concept based on a "first principals" understanding, as derived from state-of-the-art CFD, of endwall flow phenomena which limit stall range.

To achieve this goal a state-of-the-art CFD code (APNASA, Adamczyk 1995) was employed in a computationally based investigation of the impact of 
independent casing bleed and injection on the stability and performance of a moderate speed fan rotor wherein the stalling mass flow was controlled by tip flow field breakdown. This investigation was guided by observed trends in endwall flow blockage as stall is approached (Smith, L. H., 1970, Koch, 1981, Kahlid, 1994, Suder, 1997, Kahlid, et al., 1998, Cho, D. L., 1995), and based on the hypothesis that application of endwall bleed or injection can mitigate these trends (Koch and Smith, 1968a \& 1968b, Smith \& Cumpsty, 1982, Crook, et al., 1993). The best bleed and injection configurations were then combined to yield a self recirculated casing treatment concept that provided a significant increase in stall range and compressor efficiency by reducing the casing endwall blockage. Subsequent application of this approach to a high speed transonic rotor successfully yielded similar improvements in stall range with no loss in compressor efficiency.

\section{NOMENCLATURE}

$\mathrm{P}$

$\mathrm{P}_{\mathrm{t}}$

$\mathrm{T}_{\mathrm{t}}$

$\mathrm{U}_{\text {tip }}$

$\mathrm{V}$

a

$\mathrm{m}$

$\mathrm{m}_{\text {choke }}$

$\mathrm{r}$

$\alpha$

$\beta$

$\gamma$

$\rho$

$\omega$

\section{Subscripts}

$\begin{array}{ll}1 & \text { Bleed port } \\ 2 & \text { Injection port } \\ \text { abs } & \text { Absolute frame of reference } \\ \mathrm{c} & \text { Flow path casing } \\ \mathrm{n} & \text { Normal component } \\ \mathrm{t} & \text { Rotor blade tip } \\ \mathrm{x} & \text { Axial component }\end{array}$

\section{COMPUTATIONALLY BASED STUDY}

A computationally based study of various casing bleed and injection configurations was performed using the Average Passage code (APNASA) developed by Adamczyk, 1985. APNASA is a 3D time-averaged Navier-Stokes code developed for multistage compressor analysis. For these simulations the CMOTT k-e turbulence model was used (Shih, et al., 1995 \& 1996). The simulations were of an isolated blade row using an axisymmetric mass flow boundary condition (Shabbir. A., et al.,
1997) to simulate casing bleed and injection. The upstream boundary condition was prescribed at standard day inlet conditions with $5 \%$ boundary layer thickness, based on span, on both endwalls. The downstream hub static pressure was set and adjusted in steps to develop a prediction of the rotor speed line for various casing bleed/injection configurations. Convergence was deemed to be achieved when the mass flow rate, pressure ratio, efficiency, and number of separated points remained essentially constant with increasing iteration count.

As stall is approached the number of separated points in the flow field and other flow field parameters may vary as a function of iteration count. However, the simulation approaches a limit cycle in which the peak-to-peak amplitude of the flow field differences does not grow with increasing iteration count. Away from stall the convergence is well behaved with little or no variation with increasing iterations. The predicted stall point was judged to be the last stable condition prior to incurring, for a fixed hub static pressure, a continual drop in mass flow rate and pressure ratio with increasing iteration count.

The ability of the APNASA code to predict the stalling mass flow rate for an isolated transonic rotor (R35) has been demonstrated by Van Zante, et al. (1999), see Figure 1. Van Zante, et al. concluded that accurate prediction of the stable operating range requires careful attention to grid resolution near the casing. Also shown in Figure 1 is a comparison of the measured and predicted stalling mass flow rates for the transonic rotor studied herein (R67). Though the question still remains as to whether the code can adequately predict stall for any rotor, it was deemed reasonable to expect that if the code predicts an improvement in stall range that such would be realized experimentally, though perhaps to a different degree.

A moderate speed fan rotor was selected for the computationally based investigation of the impact of casing endwall bleed and injection on rotor performance. The fan rotor had 18 blades, an inlet tip radius of $28.13 \mathrm{~cm}$, a hub-tip radius ratio of 0.426 , an aspect ratio of 2.75 , a tip solidity of 0.6 , and an axial chord of $5.87 \mathrm{~cm}$ at the tip and $5.82 \mathrm{~cm}$ at the hub. The rotor tip clearance gap was modeled (by enforcement of periodicity across the tip gap) at $6.8 \%$ of tip axial chord ( 3 times the design clearance) to assure that the tip flow field would control the stall point. Based on simulation results at $8750 \mathrm{RPM}$, the choking mass flow rate at that speed is 38.995 $\mathrm{kg} / \mathrm{sec}$ based on simulations, the blade tip speed is $258 \mathrm{~m} / \mathrm{sec}$ $(846 \mathrm{ft} / \mathrm{s})$, the total-to-total pressure ratio is 1.22 , and the adiabatic efficiency is $87.3 \%$. The mesh size used for the simulations of the moderate speed fan is 162 axial x 51 radial $x$ 55 tangential nodes with 10 cells in the rotor tip clearance gap.

Though this fan performance is not commensurate with that of modern fans, as a representative tip critical flow field generator, this fan case was considered suitable for investigating the benefits of casing endwall bleed and injection. To assess the general applicability of the "lessons learned" from the moderate speed fan simulations, subsequent simulations of the "best" candidate casing treatment would be evaluated on a high-speed fan rotor with good performance (R67). 


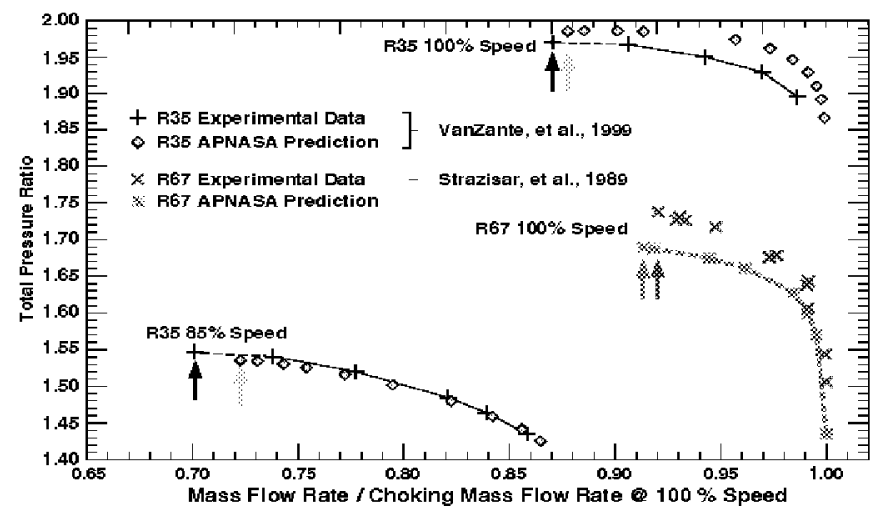

Figure 1 Comparison of predicted and measured stalling massflow rates for two transonic rotors.

The investigation was guided by reported observations (Smith, L. H., 1970, Koch, 1981, Kahlid, 1994, Suder, 1997, Kahlid, et al., 1998, Cho, D. L., 1995) that endwall aerodynamic blockage accumulates rapidly as a fan/compressor approaches stall. The accumulation of low momentum endwall fluid is exacerbated by the incoming low momentum "boundary layer" fluid adjacent to the endwall, blade/endwall flow field interactions, shock/vortex interactions, shock/tip-leakage-jet interactions, radial migration of low momentum fluid to the endwall, etc. It was hypothesized that directly controlling the low momentum producing mechanisms would reduce the rate of accumulation of endwall blockage thereby improving rotor endwall performance and as a result increasing fan/compressor stall range.

An investigation of the impact on compressor performance of various bleed and injection locations was thus conducted using computational simulations including a model for simulating casing endwall bleed and injection. The uncoupled bleed and injection cases were simulated with the bleed and injection port mass flow rates fixed at nominally $1 \%$ of the compressor mass flow rate, and the axial extent of the ports fixed at $10 \%$ of rotor tip chord. This investigation attempted to simulate the benefits of using endwall bleed to remove low momentum fluid near the endwall, thereby reducing endwall blockage. The benefits of injection were also simulated based on using high relative-total-pressure fluid to "energize" low momentum endwall fluid, thus reducing endwall blockage accumulation. The best candidate bleed and injection configurations were then simulated in a "coupled" fashion whereby the low momentum fluid bled off the casing endwall was recirculated upstream to supply fluid for the optimum injection configuration. It was envisioned that relying on the positive static pressure gradient across the rotor to self recirculate the low momentum fluid bled from the casing endwall to supply high relative total pressure fluid to the injection point would provide performance benefits from both bleed and injection. This is not a new concept as there is are existing patents (Koff, et al., 1994, Hobbs, 1995, Nolcheff,
1996) for such a casing treatment concept. The selfrecirculating casing treatment concept reported herein additionally provides:

1) A description of the methodology for identification and direct control of the most significant endwall blockage producing mechanisms limiting blade endwall performance (efficiency and stall range), and

2) Implementation of discrete single-pass recirculation to prevent continuous recirculation of high entropy fluid.

The rationale for determining the axial extent of the bleed and injection ports as well as the recirculated mass flow rate will be described later in the Results and Discussion.

As will be shown herein, directly controlling the fluid mechanisms producing endwall blockage results in a decrease in endwall blockage production and a consequent predicted improvement in both stall range and efficiency. These predicted performance improvements are a result of a CFD based fundamental understanding of the endwall fluid mechanisms most important to control, and how best to configure the bleed and injection ports to achieve efficiency and stall range improvement. Table 1 lists the bleed, injection, and coupled configurations established for simulation to predict their potential performance benefits. Also included in table 1 are the figure symbols commensurate with each case plotted in the succeeding figures, as well as the predicted range increase for each case.

\section{RESULTS AND DISCUSSION}

Figure 2 shows a comparison of the computational results of a study of casing bleed. Each of the bleed cases were selected to bleed off endwall fluid identified from CFD simulations as potential contributors to endwall blockage production. Both mass averaged total pressure ratio and adiabatic efficiency are presented in Figure 2. As evident from Figure 2, casing endwall bleed is in most cases beneficial, but in some instances can be detrimental to overall performance. The performance parameters in Figure 2 are based on a control volume analysis of the rotor, and therefore take into account the energy of the fluid entering and leaving the control volume, including that which crosses the casing boundary. As such, no credit to performance is obtained from bleeding off low momentum fluid unless the gains are accrued from increased aerodynamic performance. The "\% range extension" indicated in this and subsequent figures is the increase in mass flow range relative to the smooth wall mass flow range (mass flow range $=$ choke flow rate - stalling flow rate). Thus, no credit to stall range increase is given for increased pressure rise capability.

Figure 3 shows a comparison of the computational results of a study of endwall injection. Each of the injection cases were selected to affect control over a specific endwall fluid mechanism (e.g., leakage vortex, endwall boundary layer, etc., see Table 1) identified from CFD simulations to be a 
Table 1 Moderate Speed Fan Bleed, Injection, and Coupled Cases Investigated

\begin{tabular}{|c|c|c|c|c|c|c|c|c|}
\hline & \multirow{2}{*}{$\begin{array}{l}\text { Low momentum fluid targeted in this } \\
\text { investigation }\end{array}$} & \multirow{2}{*}{ 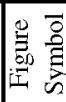 } & \multicolumn{2}{|r|}{$\%$ Rotor Chord } & \multirow{2}{*}{ 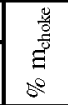 } & & & \multirow{2}{*}{$\begin{array}{l}\text { \% Range } \\
\text { Increase }\end{array}$} \\
\hline & & & กิ & - & & & & \\
\hline \multirow{8}{*}{$\begin{array}{l}n \\
\vec{d} \\
\frac{d}{m}\end{array}$} & Bleed inlet "boundary layer" fluid & $\mathbf{z}$ & & 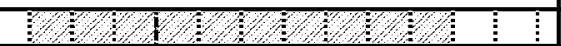 & -1.3 & & 26 \\
\hline & Bleed tip gap leakage jet blockage & A & & W/ $/ \% / \%$ & -0.1 & \multicolumn{2}{|c|}{ 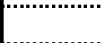 } & 45 \\
\hline & 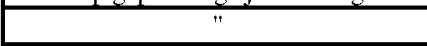 & $\mathbf{x}$ & & ( & -1.3 & & 12 \\
\hline & & $\mathbf{M}$ & & 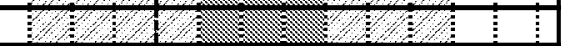 & -2.3 & \multicolumn{2}{|c|}{ 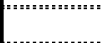 } & -34 \\
\hline & Bleed blockage aft of leakage jet & 0 & & H/ $/ \% / \% / \%$ & -1.3 & & 21 \\
\hline & " & $\Delta$ & & ७० / / / / & -2.6 & & 42 \\
\hline & & (1): & & 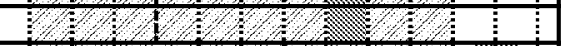 & -3.5 & \multicolumn{2}{|c|}{ 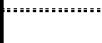 } & 55 \\
\hline & Bleed casing exit blockage & $\overline{7}$ & & H/ \% \% & -2.6 & \multirow{2}{*}{\multicolumn{2}{|c|}{\begin{tabular}{|l|l|}
\multicolumn{2}{|l|}{} \\
$\alpha$ & $\beta$ \\
$\alpha$
\end{tabular}}} & 60 \\
\hline & & & & \% $/ \% / \% / \% / \%$ & & & & \\
\hline \multirow{3}{*}{$\begin{array}{l}\text { П } \\
\stackrel{0}{\Xi} \\
\end{array}$} & Energize casing inlet fluid & 4 & $\overline{1}$ & 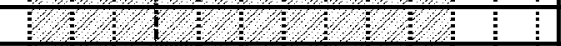 & 1.3 & \multirow{4}{*}{\multicolumn{2}{|c|}{\begin{tabular}{|l|l|}
-30 & 0 \\
-30 & 0 \\
-90 & 0 \\
& \\
\end{tabular}}} & -28 \\
\hline & Energize tip gap leakage fluid & 4 & & $1 \% \% / \% / \%$ & 1.3 & & & 38 \\
\hline & & 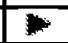 & & 2\% \% \% \% & 1.3 & & & 6 \\
\hline & & & & 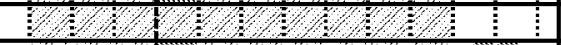 & & & & \\
\hline \multirow{3}{*}{$\frac{\bar{D}}{\overparen{Z}}$} & \multirow{3}{*}{$\begin{array}{l}\text { Coupled Bleed and Injection } \\
\text { B - Bleed low monentum exit fluid } \\
\text { I - Energize tip gap leakage fluid }\end{array}$} & $\$$ & $\overline{1}$ & 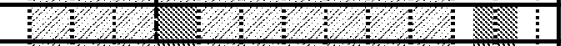 & 1.2 & -30 & 0 & 43 \\
\hline & & 4 & 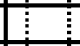 & \% / \% \% \& & 1.9 & -60 & 0 & 64 \\
\hline & & 5 & $\vdots$ & \% \% / \% & 1.9 & -30 & 0 & 60 \\
\hline
\end{tabular}

potential contributor to endwall blockage production. For all moderate speed fan cases studied the absolute flow angle of the injected fluid was set at zero degrees, which based on CFD simulations at the design conditions produced a relative flow angle approximately aligned to the local blade tip mean camber angle. It's evident from Figure 3 that casing mass injection can hurt or help overall performance, and in one case has the potential for increasing adiabatic efficiency. The injection case that produced an increase in adiabatic efficiency, and stall range, is the case that impacted the most significant blockage producing mechanism identified from the CFD simulations, in this case the tip leakage vortex. As will be shown for the best coupled bleed and injection configuration a significant reduction in endwall blockage results, which improves rotor efficiency and increases stall range.

Based on the results of these independent computationally based studies of casing bleed and injection additional simulations were performed which coupled the best bleed and injection cases to model a self-recirculating casing treatment. The coupled self-recirculating casing treatment model employed in the simulations is illustrated in Figure 4. The model requires the injected and bleed mass flow rates $\left(\mathrm{m}_{2}\right.$ and $m_{1}$ ) to be the same, and the total temperature of the injected fluid $\left(\mathrm{T}_{\mathrm{t}, 2}\right)$ to be that of the mass averaged total temperature of the fluid bled from the rotor flow field $\left(T_{t, 1}\right)$. The total pressure of the injected fluid $\left(\mathrm{P}_{t, 2}\right)$ is derived from the average static pressure of the bled fluid $\left(\mathrm{P}_{1}\right)$ plus the mass averaged dynamic pressure of the bled fluid $\left(1 / 2 \gamma \mathrm{P}_{1} \mathrm{M}_{\mathrm{abs}, 1}{ }^{2}\right)$ with an assumed loss $(\omega=0.20)$ in dynamic pressure due to bleed cavity entrance losses and loss incurred within the re-circulated casing treatment flow path.

The injected fluid should be directed to lie along the casing endwall to energize the low momentum fluid in the vicinity of the casing endwall. The injection port should be located just upstream of the region of low momentum fluid (identified by the region of low relative total pressure) to be energized, see Fig. 5. The absolute flow angle of the injected fluid should be set such that, in the frame of reference relative to the rotor, the fluid is aligned with the local rotor blade tip mean camber angle. The mass flow recirculated through the casing treatment should initially be sized commensurate with the local mass flow deficit in the rotor blade tip-clearance gap, Eq. 1 (i.e., typically that mass flow associated with the over tip leakage vortex which contributes most to the endwall blockage accumulation). The velocity of the injected fluid in the frame of reference of the casing, $V_{2}$, will be that dictated by the pressure ratio between the bleed and injection ports and the pressure losses associated with the casing treatment, Fig. 4 and Eq. 2. To the extent possible by the available pressure rise across the rotor and the absolute angle of injection, it is desirable to attempt to achieve a relative velocity for the injected fluid commensurate with the free stream velocity away from the influence of the tip clearance flow. With the initially established mass-flow rate through the casing treatment, the prescribed injection angles, and the pressure ratio set by the location of the bleed and injection ports the 


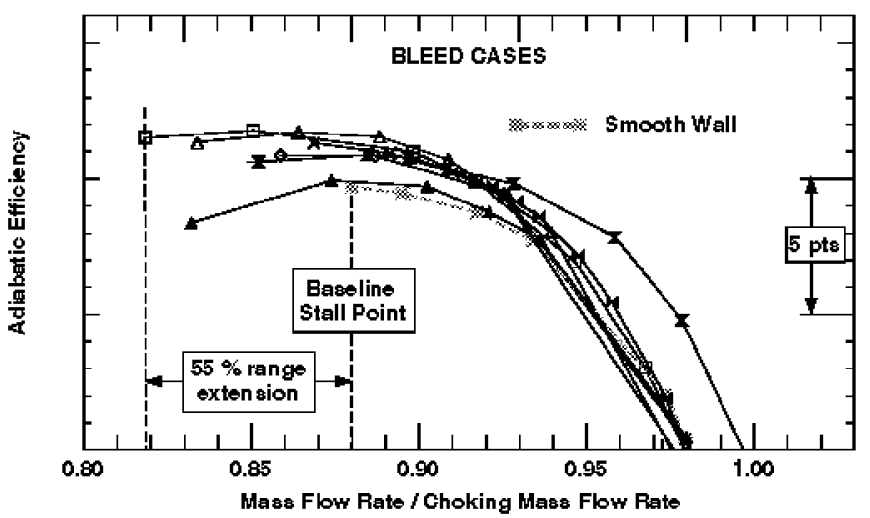

a) Adiabatic Efficiency

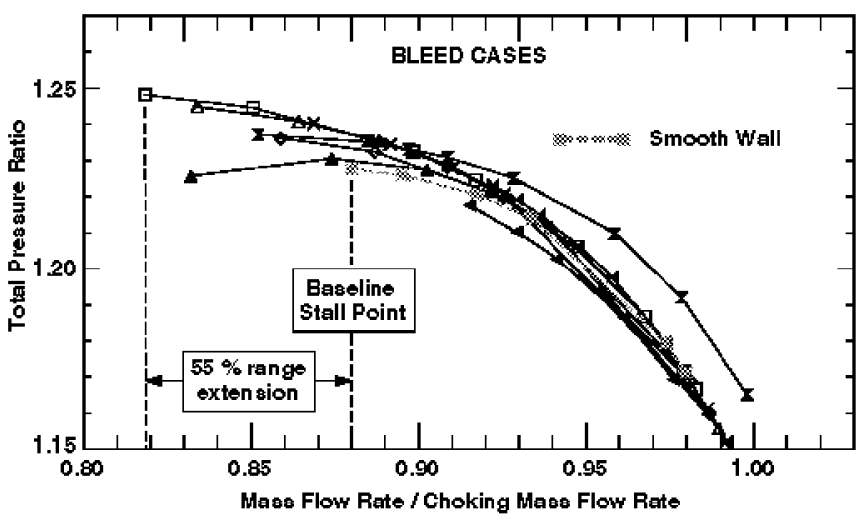

b) Total Pressure Ratio

Figure 2 Casing Bleed Cases Applied to Moderate Speed Fan Rotor.

area of the injection port is established, Eq. 4. The bleed port area is sized to accommodate the injection mass flow rate and to insure that the flow will not choke at the bleed port.

Eq. $1 \quad \mathrm{~m}_{2}=\rho_{\mathrm{t}} \mathrm{V}_{\mathrm{x}, \mathrm{t}} \pi\left(\mathrm{r}_{\mathrm{c}}^{2}-\mathrm{r}_{\mathrm{t}}^{2}\right)-2 \pi \int_{\mathrm{r}_{\mathrm{t}}}^{\mathrm{r}_{\mathrm{c}}} \rho_{2} \mathrm{~V}_{\mathrm{x}, 2} \mathrm{rdr}$

Eq. $2 \quad \mathrm{~V}_{2}=\sqrt{\frac{2 \gamma \operatorname{Rg}_{\mathrm{c}}}{\gamma-1} \mathrm{~T}_{\mathrm{t}, 2}\left[1-\left(\mathrm{P}_{2} / \mathrm{P}_{\mathrm{t}, 2}\right)^{(\gamma-1) / \gamma}\right]}$

Eq. $3 \quad \mathrm{~V}_{\mathrm{n}, 2}=\mathrm{V}_{2} \sin \alpha_{2}$

Eq. $4 \quad \mathrm{a}_{2}=\mathrm{m}_{2} /\left(\rho_{2} \mathrm{~V}_{\mathrm{n}, 2}\right)$

At the completion of each flip of the APNASA simulations the bleed and injection boundary conditions are updated. This is accomplished with an external FORTRAN program which mass averages the flow conditions over the bleed and injection ports and then imposes the casing

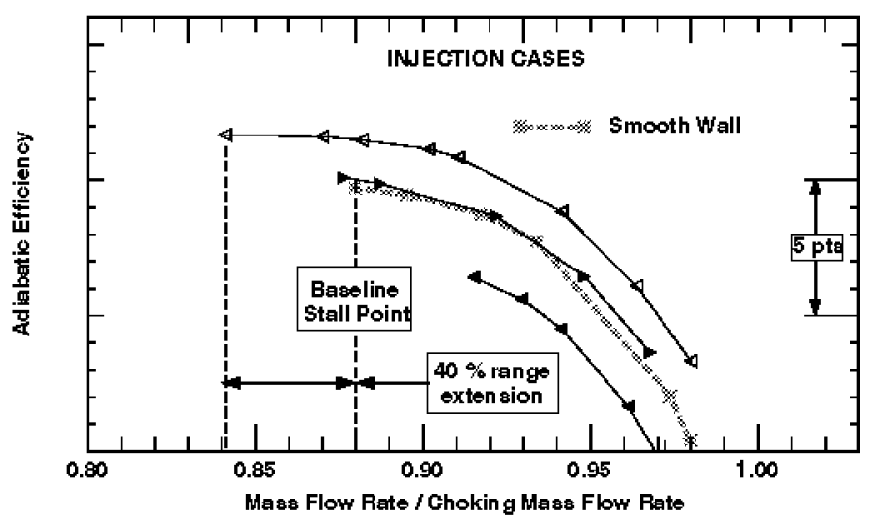

a) Adiabatic Efficiency

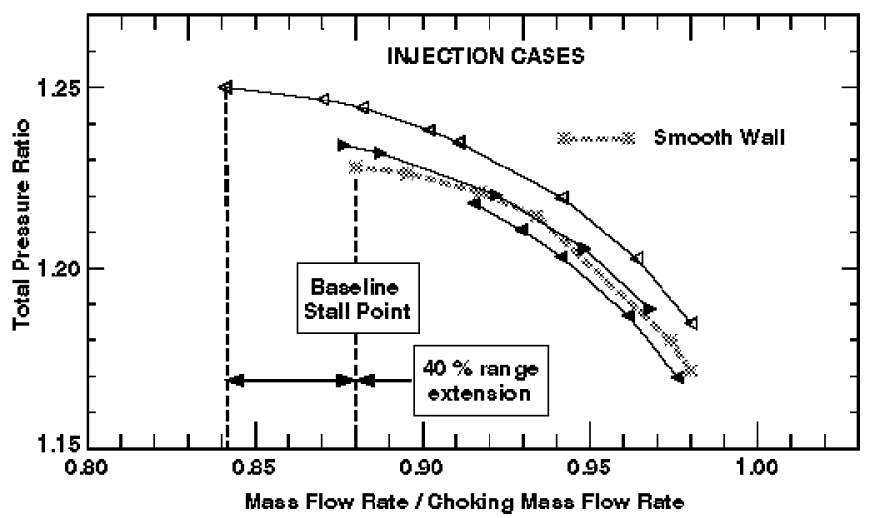

b) Total Pressure Ratio

Figure 3 Casing Injection Cases Applied to Moderate Speed Fan Rotor.

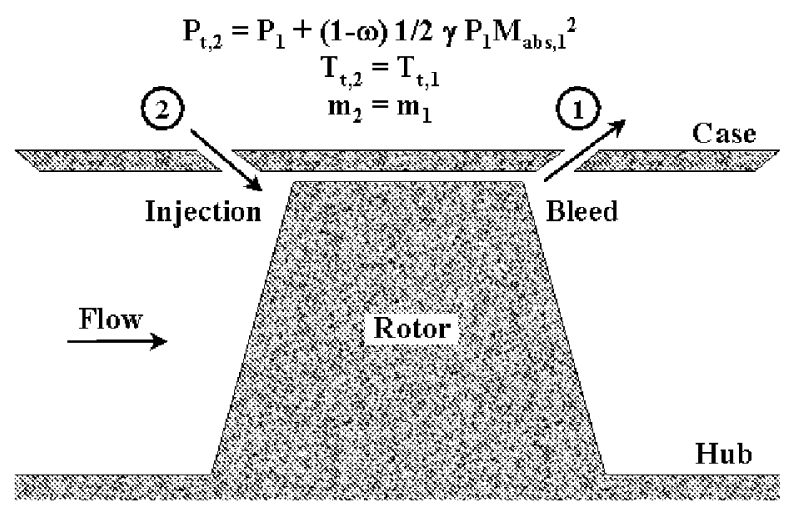

Figure 4 Self-Recirculating Casing Treatment Model.

treatment model and the prescribed injection and bleed port conditions as described above. The simulation is converged when both the APNASA convergence criteria are met and the bleed and injection boundary condition parameters do not change from flip to flip. 


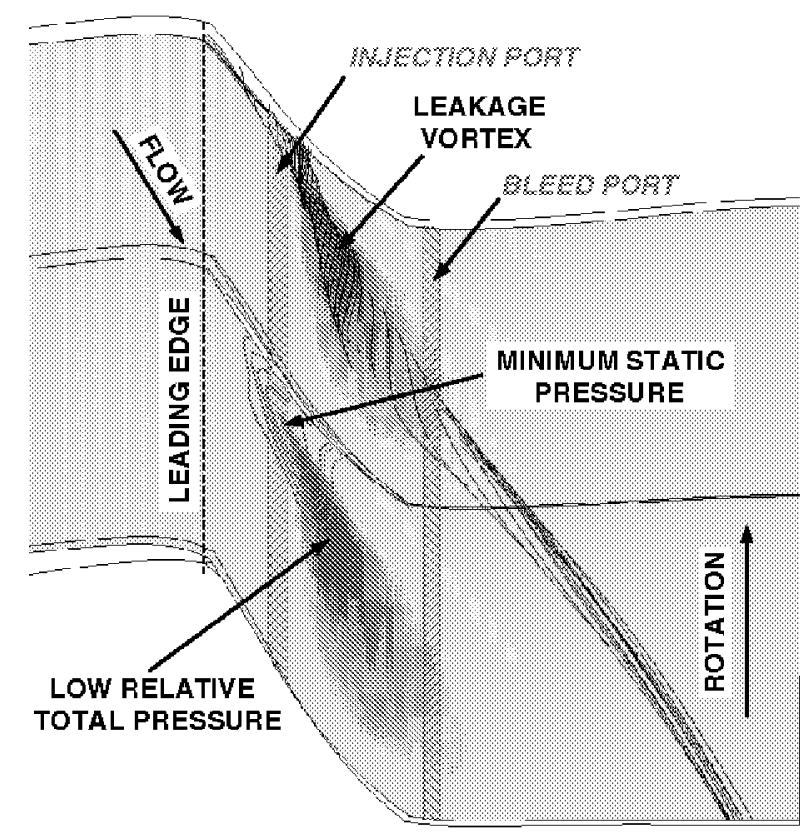

Figure 5 Relative Total Pressure Contours at Tip Section of Moderate Speed Fan Rotor Identifies Blockage Producing Mechanism to Control.

As evidenced by the results of the coupled bleed and injection casing treatment model shown in Figure 6, not only does the self-recirculating casing treatment concept provide increased range it also has potential for increasing total pressure rise capability of the rotor and adiabatic efficiency. This occurs due to the effectiveness of the casing treatment in reducing the endwall blockage, thus enabling the blade tip elements to impart more work to the fluid, and in a more efficient manner. As indicated by the differences in the selfrecirculated casing treatment results presented in Figure 6, implementation is important for maximum benefit. However, all cases presented provided range increase with no decrement in efficiency from the smooth untreated case

Evidence supporting the predicted performance improvements are provided in Figure 7 which shows a comparison of relative total pressure contours between the self-recirculated casing treatment case and the smooth untreated case. As shown in Figure 7 the extent of low relative total pressure accumulated near the casing endwall is significantly less for the case employing the self-recirculating casing treatment model relative to the smooth untreated case.

The impact of the endwall blockage reduction on the fan rotor blade-element performance is indicated in figure 8 . As is evident from figure 8, for each case plotted the fan rotor efficiency is essentially unchanged across the rotor blade span until just out board of about $75 \%$ span. Beyond $75 \%$ span there is a marked improvement in the blade element performance even for the lower flow rates obtained as a result

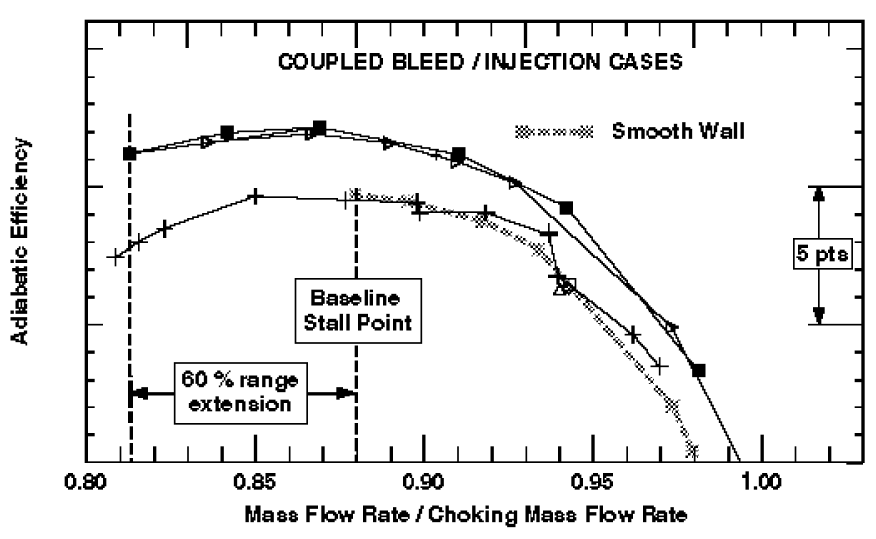

a) Adiabatic Efficiency

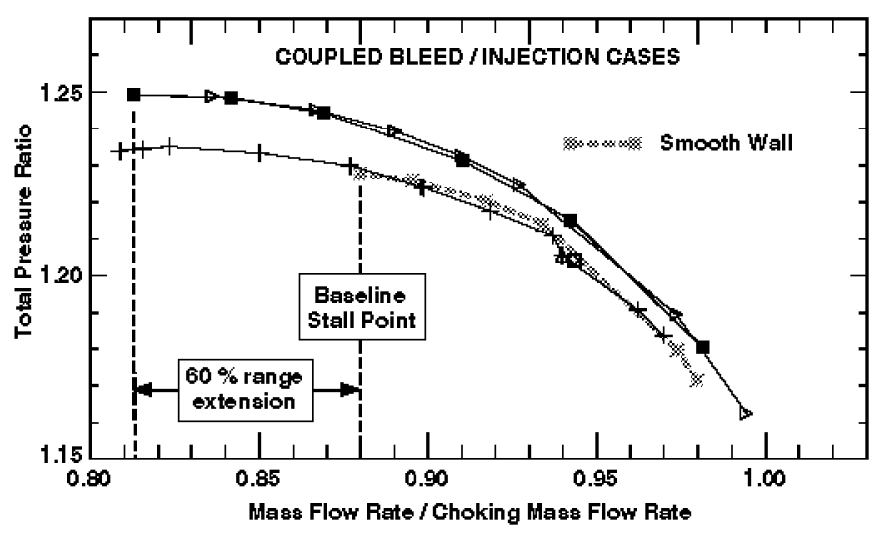

b) Total Pressure Ratio

Figure 6 Coupled Bleed / Injection Cases Applied to Moderate Speed Fan

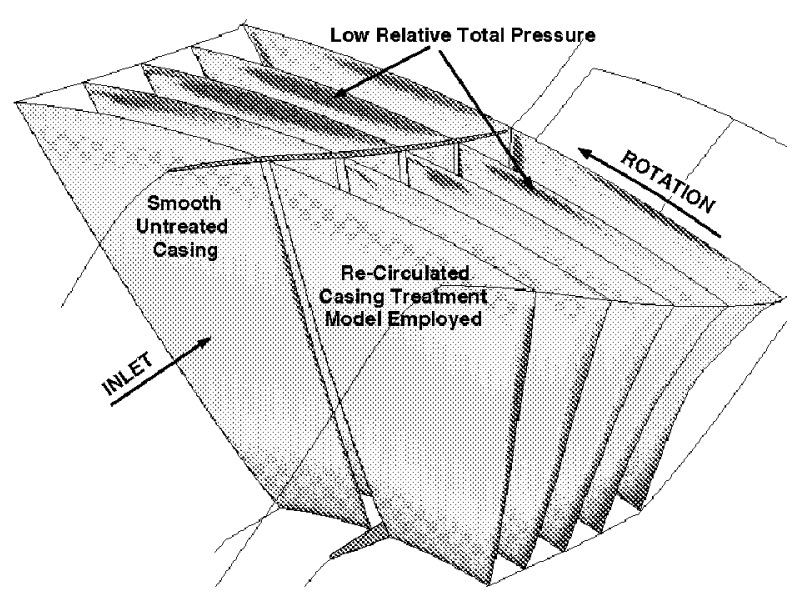

Figure 7 Comparison of Relative Total Pressure Contours for Smooth and Treated Casing Endwalls of Moderate Speed Fan Rotor. 


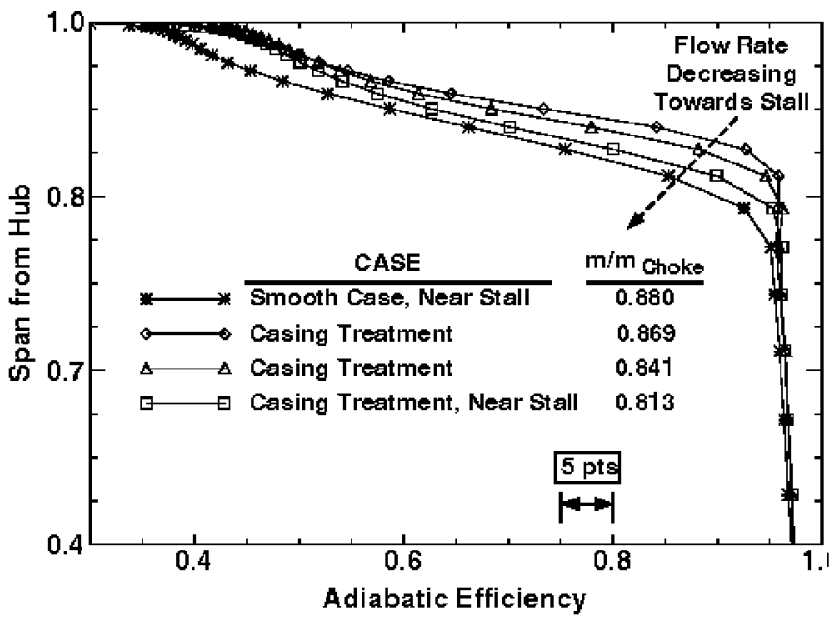

Figure 8 Spanwise distributions of adiabatic efficiency for the moderate speed fan with and without recirculated casing treatment.

of the recirculated casing treatment relative to the untreated (smooth case) stalling mass flow rate.

The moderate tip speed fan study provided a fundamental understanding of the fluid mechanisms important to control to obtain improvement in stall range without a decrement in efficiency. A concept for implementing a self-recirculating casing treatment was formulated and demonstrated by the results of the simulations with the coupled bleed and injection model as applied to this moderate speed tip-critical fan.

To assess how generic this self-recirculated casing treatment concept is it was applied to an efficient transonic fan rotor, NASA Rotor 67, Strazisar, et al. (1989). Rotor 67 measured peak adiabatic efficiency is reported at $93 \%$, at $34.573 \mathrm{~kg} / \mathrm{sec}(76.06 \mathrm{lbm} / \mathrm{sec})$ achieving 1.642 total-to-total pressure ratio, at design speed, $\mathrm{U}_{\text {tip }}=429 \mathrm{~m} / \mathrm{sec}(1409 \mathrm{ft} / \mathrm{sec})$. The measured efficiency spiked to $93 \%$ at essentially a single mass flow rate and dropped to $91 \%$ for a less than $1 \%$ change in mass flow rate.

The results of APNASA simulations of Rotor 67 without casing treatment were used to guide the configuration of the self-recirculating casing treatment concept to be employed for Rotor 67 . The fluid mechanism identified from the simulations to be most responsible for producing endwall blockage for Rotor 67, see Fig. 9, was similar though somewhat different from that identified for the moderate speed fan rotor, see Fig. 5. The presence of a passage shock terminating on the suction surface in the region of low relativetotal-pressure fluid caused concern for locating an injection port there. Furthermore, unlike the moderate tip speed fan case the leakage vortex, which was identified as most responsible for casing endwall blockage production, moved upstream as the rotor was throttled towards stall. Therefore the injection port was located near the blade leading edge to affect control over the leading edge vortex and tip section loading with the

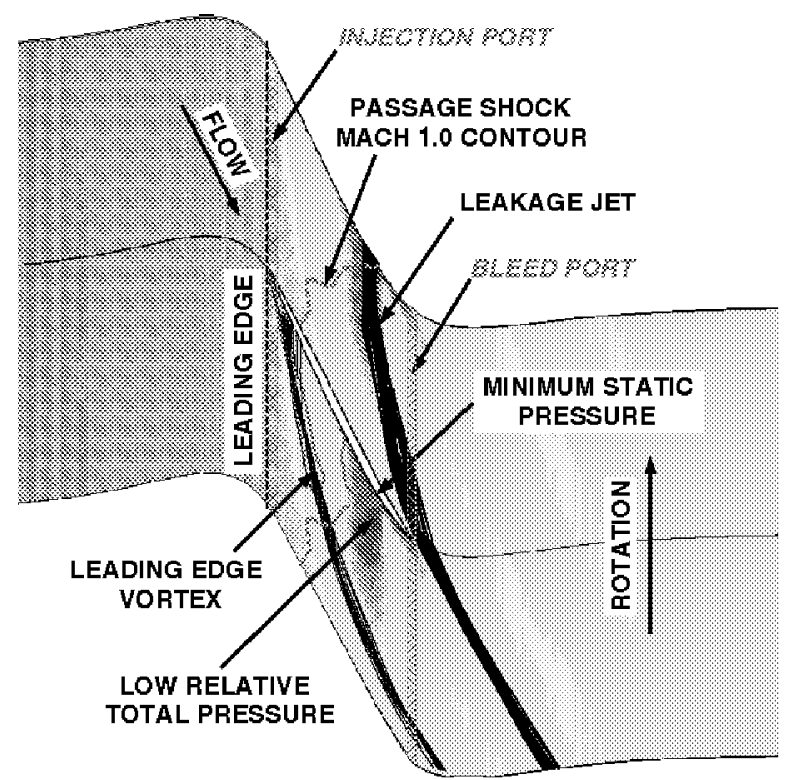

Figure 9 Relative Total Pressure Contours at Tip Section of Transonic Fan Rotor 67 Identifies Blockage Producing Mechanism to Control.

expectation that it would beneficially impact the extent of low relative total pressure leaking across the blade tip gap. The results shown in Figure 10 show the self-recirculated casing treatment concept employed (where $\omega=0.20$ ) does provide benefits to Rotor 67 performance. Significant stall range increase was predicted with no decrement in rotor efficiency.

Since Rotor 67 already has good stall range capability, and as a test of the applicability of the concept to effectively extend stall range for a distorted inlet condition, simulations of Rotor 67 with and without inlet distortion were conducted. The distorted and undistorted inlet profiles are shown in Figure 11. The distortion was only applied to the casing endwall to reduce stall range relative to the undistorted case. As shown in Figure 12 the self-recirculated casing treatment concept also provides considerable benefit in extending the stall range when there is an inlet distortion. Although neither the distorted or undistorted cases showed improved efficiency as a result of the self-recirculated casing treatment they both show significant range increase without the usual decrement in efficiency relative to the baseline untreated case.

Previous investigations of discrete upstream casing tip injection for stability enhancement (Hathaway and Strazisar, 1998, Suder, et al., 2000) demonstrated that discrete tip injection with as few as three injectors provided essentially the same range extension as twelve injectors. The main requirement for range extension was shown to be the injected/free-stream velocity ratio. The potential for stall range improvement with lower loss using part-circumference casing treatment has been shown by Cumpsty, 1989. Based on these reported results it is proposed that further improvement in 


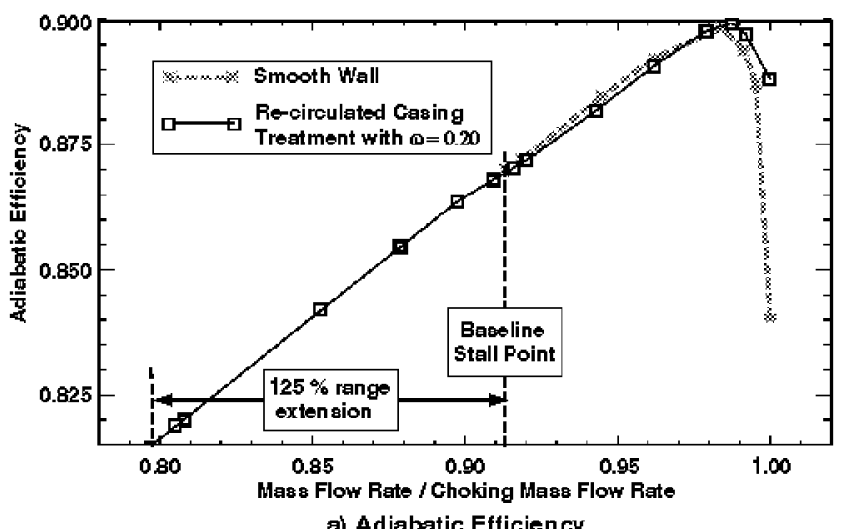

a) Adiabatic Efficiency

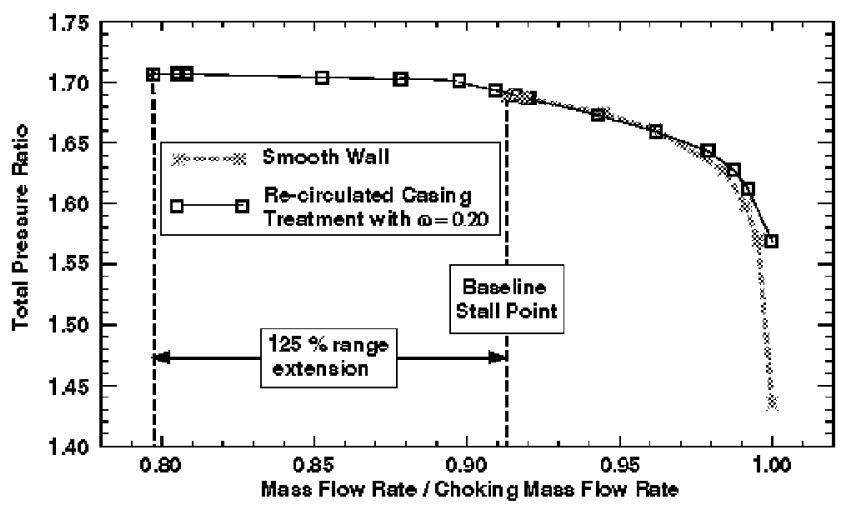

b) Total Pressure Ratio

Figure 10 Re-Circulated Casing Treatment Model Applied to Transonic Fan Rotor 67 without Inlet Distortion.

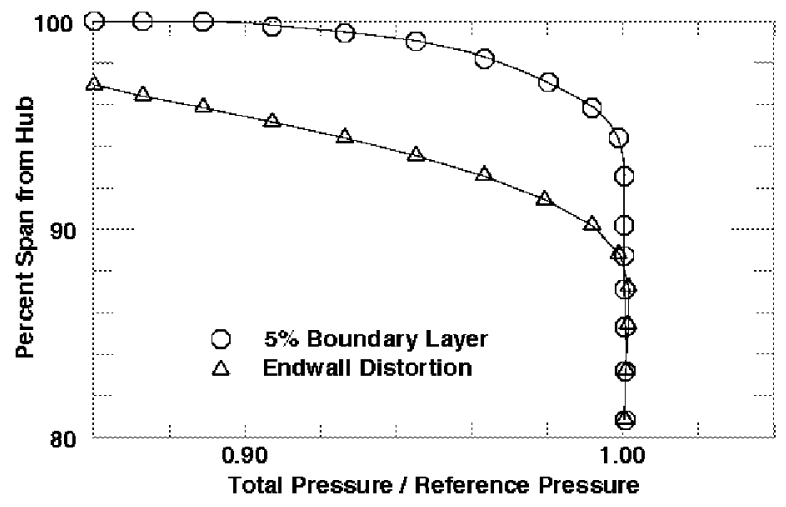

Figure 11 Rotor 67 Distorted and Non-Distorted Inlet Total

Pressure Profile Applied to Transonic Fan Rotor 67.

existing re-circulating casing treatments could be realized by implementing a discrete self-recirculating casing treatment concept. Figure 13 shows a representation of such a concept. As shown in Figure 13 low momentum fluid is bled through discrete bleed ports along the compressor casing near the blade trailing edge (or where an available source of sufficient high-
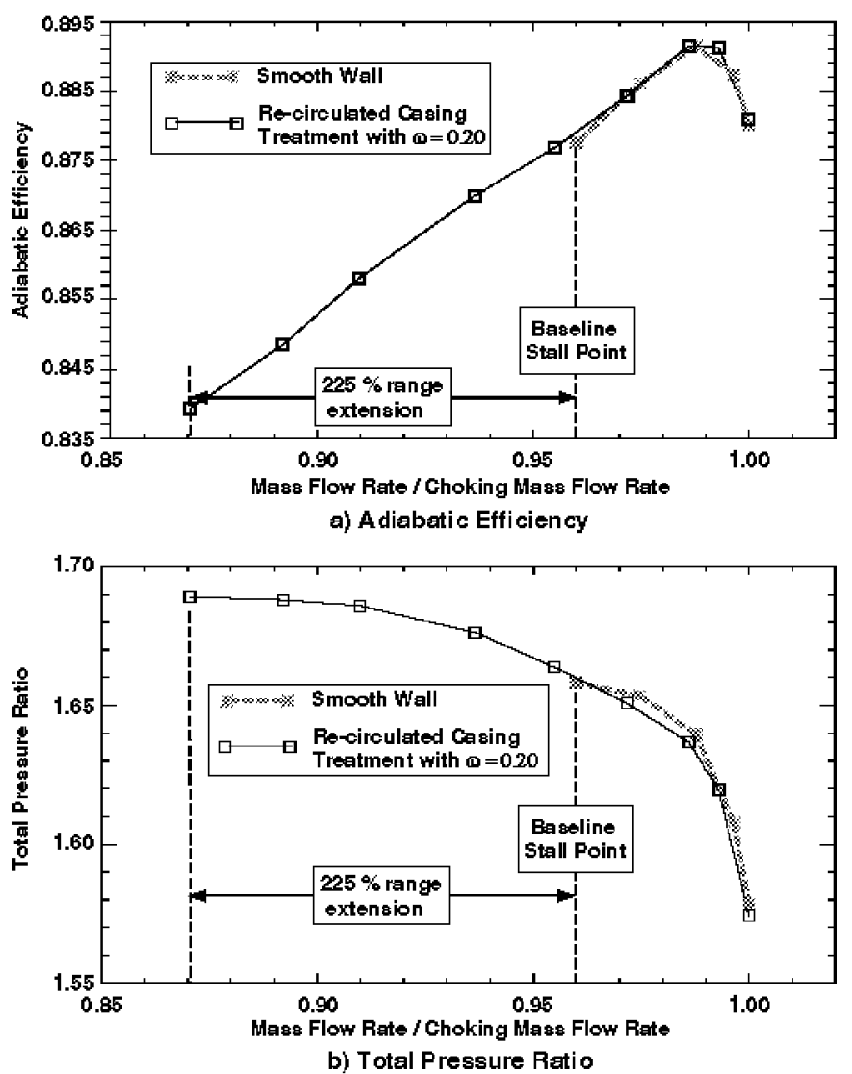

Figure 12 Re-Circulated Casing Treatment Model Applied to Transonic Fan Rotor 67 with Inlet Distortion.

pressure fluid can be obtained). The low momentum fluid bled off via the bleed ports is then de-swirled as necessary and accelerated through a convergent channel where it is reinjected into the blade passage via discrete injection ports located near the blade leading edge (or where deemed most beneficial to overall performance). Due to the increased static pressure of the bleed fluid relative to the injection fluid in the rotor frame of reference the casing treatment increases the relative total pressure of the fluid in the casing treatment flow path. The injection ports are circumferentially displaced relative to the bleed ports to preclude the potential for reingestion of the injected fluid into the bleed ports. This alleviates the tendency for typical self-recirculating casing treatments to produce excessively high temperatures along the case and in the casing treatment flow path due to re-working continually re-circulated fluid which can result in melting of the casing treatment components (Kerney, P., 1994).

\section{CONCLUSIONS}

A self-recirculating casing treatment concept has been demonstrated via CFD simulations to provide a considerable benefit in stall range extension with no predicted loss in efficiency or total pressure rise capability. The concept is shown to benefit performance by decreasing the extent of low 
relative total pressure fluid typically accumulating in the casing endwall region as stall is approached (i.e., endwall blockage). The key aspects for consideration in assuring maximum stall range increase without the usual decrement to efficiency are:

1) Target the major contributor to endwall blockage accumulation, typically the leading-edge or tipclearance vortex, and locate the injection port commensurate with such.

2) Assure that the injected fluid is aligned in the relative frame with the blade mean camber angle.

3) Inject at high relative velocity to energize the low momentum fluid compromising blade row performance (i.e., attempt to match the injected velocity to be commensurate with the design intent).

4) Inject sufficient fluid to fill the mass deficit associated with the leakage vortex, but limit the amount of injected fluid so as not to adversely impact the spanwise loading distribution outside of the vicinity of the blade tip clearance gap.

5) Locate and size the bleed port to provide sufficient pressure rise for 3) and 4) while not allowing the bleed port to be the choking element.

6) Implementation of discrete bleed and injection ports which are circumferentially displaced to prevent reingestion of injected fluid into the bleed ports.
Though the CFD predictions presented herein have shown the potential for this casing treatment concept to provide significant range extension with out the usual attendant loss of efficiency they have only considered range extension at design speed conditions. Any general assessment of its effectiveness must include consideration of the potential for range extension at off-design conditions. The extent to which the fluid mechanism identified as most responsible for blockage production at design speed conditions contributes to blockage production at off-design conditions must be considered for assessing the general applicability of the casing treatment concept. The results of Suder et al, 2000 showing increased effectiveness of upstream casing injection (similar to the concept reported herein except for the location of the injection point) at off-design conditions suggests the possibility for general applicability of the casing treatment concept presented herein.

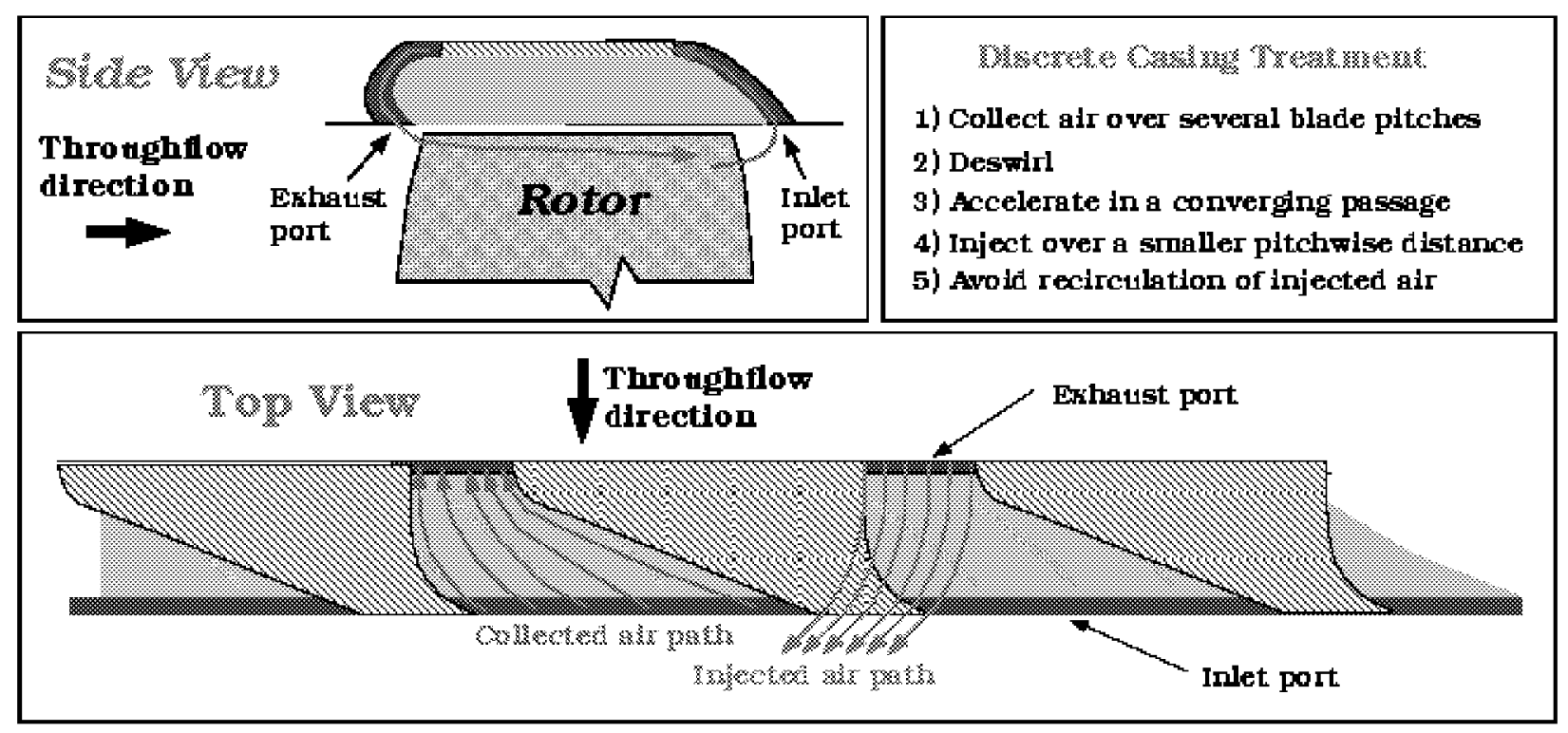

Figure 13 Discrete Recirculating Casing Treatment Concept 


\section{REFERENCES}

Adamczyk, J. J., "Model Equation for Simulating Flows in Multistage Turbomachinery," ASME Paper No. 85-GT-226, 1985.

Cho, D. L., "Effect of Vortex Core Stagnation Pressure on Tip Clearance Flow Blockage in Turbomachines, "Masters Thesis, Massachusetts Institute of Technology, September, 1995.

Crook, A. J., Greitzer, E. M., Tan, C. S., Adamczyk, J. J., "Numerical Simulation of Compressor Endwall and Casing Treatment Flow Phenomena," ASME Journal of Turbomachinery, Vol. 115, pp. 501-512, July 1993.

Cumpsty. N. A., "Part-Circumference Casing Treatment and the Effect on Compressor Stall, " ASME paper No. 89-GT312, 1989.

Hathaway, M. D., Strazisar, A. J., "Impact of Discrete Tip Injection on Stabilization of a Transonic Compressor Rotor," $21^{\text {st }}$ Army Science Conference, Norfolk, VA, June 15-17, 1998.

Hobbs, D. E., "Active Vaned Passage Casing Treatment, " U.S. Patent (5,431.533), July 11, 1995.

Janssens, G., Chedozeau, M., "Controle du Decollement Parietal dans les Compresseurs Axiaux par Aspiration ou Soufflage de la Couche Limite, "Communication presentee au XVI Colloque d'Aerodynamique Appliquee (AAAF), Lille, 13-15 November, 1979.

Kerney, P. "Recirculating Cavity Casing Treatment Failure, “ Wright Laboratories Report WL-TR-94-2092, 1994.

Khalid, S., "The Effects of Tip Clearance on Axial Compressor Pressure Rise, " Ph.D. Dissertation, Massachusetts Institute of Technology, 1994.

Khalid, S. A., Khalsa, A. S., Waitz, I. A., Greitzer, E. M., Tan, C. S., Cumptsy, N. A. Adamczyk, J. J., Marble, F. E., "Endwall Blockage in Axial Compressors, " ASME Paper 98-GT-188, 1998.

Koch, C. C., Smith, L. H. Jr., "Experimental Evaluation of Outer Casing Blowing or Bleeding of Single Stage Axial Flow Compressor, Part IV - Performance of Blowing Insert Configuration No. 1," NASA CR-54589, 1968a.

Koch, C. C., Smith, L. H. Jr., "Experimental Evaluation of Outer Casing Blowing or Bleeding of Single Stage Axial Flow Compressor, Part IV - Performance of Bleed Insert Configuration No. 3," NASA CR-54590, 1968 b.

Koch, C. C., "Stalling Pressure Rise Capability of Axial Flow Compressor Stages, "Transaction of the ASME, Journal of Engineering for Power, Vol. 103, pp. 645-656, October, 1981.
Koff, S. G., Mazzawy, R. S., Nikkanen, J. P., Nolcheff, N. A., "Case Treatment for Compressor Blades. "U.S. Patent (5,282,718), February 1, 1994.

Nolcheff, N. A., "Flow Aligned Plenum Endwall Treatment for Compressor Blades, " U.S. Patent $(5,586,859)$, December 24, 1996.

Prince, D. C. Jr., Wisler, D. D., Hivers, D. E., "Study of Casing Treatment Stall Margin Improvement," NASA CR134552, 1974.

Shabbir. A., Celetina, M. L., Adamczyk, J. J., and Strazisar, A. J., "The Effect of Hub Leakage Flow on Two High Speed Axial Flow Compressor Rotors," ASME Paper No. 97-GT346, 1997

Shih, T. H., Liou, W. W., Shabbir, A., Zhu, J. and Yang, Z., "A New k-e Eddy Viscosity Model for High Reynolds Number Turbulent Flows, "Computers Fluids, 24, 3, 227-328, 1995.

Shih, T. H., Zhu, J. Celestina, M. L., "Assessment of Three Turbulence Models in a Compressor Rotor, " ASME Paper No. 96-GT-198, 1996.

Smith, G. D. J., Cumpsty, N. A., "Flow Phenomena in Compressor Casing Treatment, " ASME Journal of Engineering for Gas Turbine and Power, Vol. 106, pp. 532541, January 1, 1982.

Smith, L. H., "Casing Boundary Layers in Multistage AxialFlow Compressors, " Flow Research on Blading, ed., L. S. Dzung, Elsevier, Amsterdam, 1970.

Suder, K. L., Hathaway, M. D., Thorp, S. A., Strazisar, A. J., Bright, M. B., "Compressor Stability Enhancement Using Discrete Tip Injection." ASME Paper 2000-GT-0571, accepted for publication in the Transactions of the ASME, 2000.

Suder, K. L., Experimental Investigation of the Flow Field in a Transonic, Axial Flow Compressor With Respect to the Development of Blockage and Loss, " NASA TM 107310, October, 1996.

Strazisar, A. J., Wood, J. R., Hathaway, M. D., Suder, K. L., "Laser Anemometer Measurements in a Transonic Axial-Flow Fan Rotor, "NASA TP 2879, November, 1989.

Takata, H., and Tsukuda, Y. "Stall Margin Improvement by Casing Treatment - It's Mechanism and Effectiveness," ASME Journal of Engineering for Power, Vol. 99, pp. 121-133, 1977.

Van Zante, D. Z., Strazisar, A. J., Wood, J. R., Hathaway, M. D., Okiishi, T. H., "Recommendations for Achieving Accurate Numerical Simulation of Tip Clearance Flows in Transonic Compressor Rotors, " ASME Paper 99-GT-390, accepted for publication in the Transaction of the ASME, 1999. 


\section{REPORT DOCUMENTATION PAGE}

Public reporting burden for this collection of information is estimated to average 1 hour per response, including the time for reviewing instructions, searching existing data sources, gathering and maintaining the data needed, and completing and reviewing the collection of information. Send comments regarding this burden estimate or any other aspect of this collection of information, including suggestions for reducing this burden, to Washington Headquarters Services, Directorate for Information Operations and Reports, 1215 Jefferso
Davis Highway, Suite 1204, Arlington, VA 22202-4302, and to the Office of Management and Budget, Paperwork Reduction Project (0704-0188), Washington, DC 20503.

\begin{tabular}{|l|l|l} 
1. AGENCY USE ONLY (Leave blank) & $\begin{array}{c}\text { 2. REPORT DATE } \\
\text { July } 2002\end{array}$ & $\begin{array}{l}\text { 3. REPORT TYPE AND DATES COVERED } \\
\text { Technical Memorandum }\end{array}$ \\
\hline
\end{tabular}

\begin{tabular}{l|l} 
4. TITLE AND SUBTITLE & 5. FUNDING NUMBERS
\end{tabular}

Self-Recirculating Casing Treatment Concept for Enhanced Compressor Performance

6. AUTHOR(S)

Michael D. Hathaway

WU-714-03-20-00

1L161102AH45

7. PERFORMING ORGANIZATION NAME(S) AND ADDRESS(ES)

National Aeronautics and Space Administration

John H. Glenn Research Center at Lewis Field

Cleveland, Ohio 44135-3191

8. PERFORMING ORGANIZATION

REPORT NUMBER

E-13353

9. SPONSORING/MONITORING AGENCY NAME(S) AND ADDRESS(ES)

National Aeronautics and Space Administration

Washington, DC 20546-0001

and

U.S. Army Research Laboratory

Adelphi, Maryland 20783-1145

10. SPONSORING/MONITORING

AGENCY REPORT NUMBER

NASA TM-2002-211569

ARL-TR-2748

GT-2002-30368

\section{SUPPLEMENTARY NOTES}

Prepared for the Turbo Expo 2002 cosponsored by the American Society of Mechanical Engineers and the International Gas Turbine Institute, Amsterdam, The Netherlands, June 3-6, 2002. Responsible person, Michael D. Hathaway, organization code 5810, 216-433-6250.

12a. DISTRIBUTION/AVAILABILITY STATEMENT 12b. DISTRIBUTION CODE

Unclassified - Unlimited

Subject Category: 07

Distribution: Nonstandard

Available electronically at htp:/gltrs grenasa.gov/GLTRS

This publication is available from the NASA Center for AeroSpace Information, 301-621-0390.

13. ABSTRACT (Maximum 200 words)

A state-of-the-art CFD code (APNASA) was employed in a computationally based investigation of the impact of casing bleed and injection on the stability and performance of a moderate speed fan rotor wherein the stalling mass flow is controlled by tip flow field breakdown. The investigation was guided by observed trends in endwall flow characteristics (e.g., increasing endwall aerodynamic blockage) as stall is approached and based on the hypothesis that application of bleed or injection can mitigate these trends. The "best" bleed and injection configurations were then combined to yield a self-recirculating casing treatment concept. The results of this investigation yielded: 1) identification of the fluid mechanisms which precipitate stall of tip critical blade rows, and 2) an approach to recirculated casing treatment which results in increased compressor stall range with minimal or no loss in efficiency. Subsequent application of this approach to a high speed transonic rotor successfully yielded significant improvements in stall range with no loss in compressor efficiency.

\section{SUBJECT TERMS}

15. NUMBER OF PAGES

Machines for compressing air or other fluids

17. SECURITY CLASSIFICATION OF REPORT

Unclassified
18. SECURITY CLASSIFICATION OF THIS PAGE

Unclassified
19. SECURITY CLASSIFICATION OF ABSTRACT

Unclassified

NSN 7540-01-280-5500

16. PRICE CODE

20. LIMITATION OF ABSTRACT \\ 20. LIMITATION OF ABSTRACT}

